\title{
EFFECTIVE TALENT MANAGEMENT IN R\&D ORGANISATION A CASE STUDY
}

\author{
*Dr. Ritika Sinha **Mrs. M.K. Vasanthi
}

\begin{abstract}
Talent is one of the most important resource of the research organisation which enables the organisation to achieve the best results and success. Talent management is a mission critical process which ensures organizations have the highly skilled man power in place to meet the organisation's current and future research goals. One of the key factor of talent management is identification of the key gaps between the talent in place and the talent required to drive research success. Organisations are made up of people. As an organisation strives to meet its organisational goals, it must make sure that it has a continuous and integrated process for recruiting, training, managing, supporting and compensating these people. Succession planning, a very important function, enables managers and individuals to identify the right candidates for a position. Talent identification, skills acquisition and development plan improves the research works. In this paper the concept of TMand its application in $R$ $\& D$ is explored. Innovation continues to be the domain of $R \& D$ division. $R \& D$ typically refers to the "Creative work undertaken on a systematic basis in order to increase the stock of knowledge and the use of this knowledge to devise new applications."

In this research we scrutinize the way the notions of talent management relate in $R \& D$ settings and its correlation with process and design innovation that contributes to the competitive advantage of the organization. The outcome of the paper is to examine how to understand the concept of talent management applied in research and development and its effectiveness using the single case study design.
\end{abstract}

Keywords: Talent management, Research, Skills acquisition, Organization's goal, R\&D, innovation.

\section{1) INTRODUCTION}

Research and development (R\&D) procedures speed up the expansion and development of every organization as they offer a vital contribution to innovation and competitive lead. The rising significance of innovation for firms, mergers and acquisitions, and the intensification of project arrangements are resulting in several rationalizations in the organization of the research purpose. Organizations put in considerable resources in R\&D to augment long-term operation. Regardless of these outlays, related emergencies can influence innovation. These procedures should be appropriately handled; as innovations handled correctly generate value and proceeds, build up

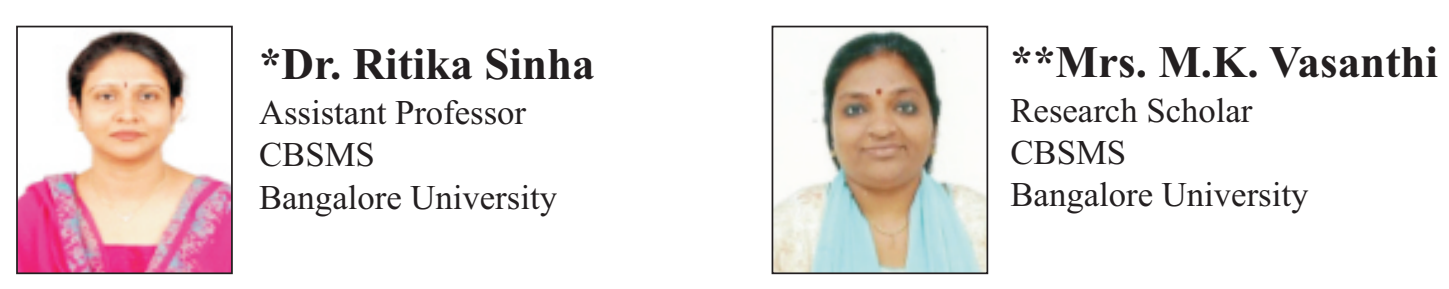


maintainable competitive advantage, draw and maintain skills, create flexible and positive organization. As human resources are an unavoidable component of every innovation procedure and $R \& D$, this research examines talent management in $R \& D$ procedures and projects. In spite of over ten years of buildup about the notion of talent management, we only possess a comparatively restricted understanding concerning its relevance in practice. In this research we scrutinize the way the notions of talent management relate in $R \& D$ settings and its correlation with process and design innovation that contributes to the competitive advantage of the organization. Research and Development is the chief foundation of development for firms, offering a vital input to innovation and therefore to competitive lead. As anticipations from R\&D are highly elevated, companies spend a great deal in it. Owing to the excessive expenditures in this field and great impact on the accomplishment of an innovation, $R \& D$ management is a vital component of the entire innovation management. R\&D should be appropriately handled, as sound $\mathrm{R} \& \mathrm{D}$ procedure produces innovations that bring about value and proceeds, build up maintainable competitive lead, draw and maintain skills, create flexible and positive organization. Companies have to be suitably organized to completely utilize their resources to achieve a competitive lead (Barney, 1997). Talent management has a vital part in supporting the organization to guarantee its human resources are used to the maximum level. An opinion exists that it is essential for an organization to understand and utilize the resulting awareness as a basis of competitive lead (Soliman \& Spooner, 2000; Hass, 2006). It is debated that some talent management procedures can back learning growth, together with the discriminatory staffing and tactical training of important employees (Haesli \& Boxall, 2005; Lopez, Peon \& Ordas, 2005, 2006). Consequently, talent management is a precise manner of drawing and maintaining the vital knowledge and abilities of the future. The universal economic environment has changed considerably ever since a faction of McKinsey consultants made up the expression "The War for Talent" that pushed the concept of talent management to the forefront for practitioners and educationalists equally. Though the economic framework might have changed fundamentally ever since the 1990s when the notion materialized, the essential basis continues to be applicable. That is a company's human resources that offers a vital basis of maintainable competitive lead (Lowe, Milliman, De Cieri \& Dowling, 2002; Caligiuri, Lazarova \& Tarique, 2005).

As "innovation significantly relies on inspired personnel who take lead and are innovative in their task and, furthermore, staff members could enhance company functioning with their capability to produce ideas and utilize them as a foundation for novel and improved goods, services and work procedures" (Načinović, Galetić \& Cavlek, 2011), it is vital to examine talent management as an unavoidable constituent of innovation procedure and research and development management.

\section{Talent management}

Talent management is considered as a crucial Human Resource challenge which organizations will confront in the next ten years (Frank, Finnegan \& Taylor, 2004; Boston Consulting Group, 2007). However, in spite of a more than ten years of dispute on the significance of talent management, the notion is not fully developed and investigated. Despite the speechmaking of tactical incorporated talent management structures in the practitioner literature, ironically the facts imply that comparatively not many organizations manage skill on a synchronized or effectual basis 
(Cappelli, 2008; Cheese, Thomas \& Craig, 2008; Sparrow, Brewster \& Harris, 2004). This is the critical ingredient for organizational success since all other resources are more or less equally available to all players in the industry. Talent management is the key factor or force behind any organization's success and hence managing the resources is of critical importance. Just having manpower does not necessarily mean that the necessary work will be taken care of. It becomes supremely critical that people in a organization are managed well.

Talent management is a crucial segment of human resources management especially in 21 st century (Heinien \& O'Neill, 2004; Ashton \& Moreton, 2005; McGee, 2006; Ingham, 2006; McCauley \& Wakefield, 2006). Classification and cultivation of talents is the very basic approach of talent management which are essential for sustaining prospective competitive edge (Frank and Taylor, 2004). Talent management procedures according to McCauley and Wakefield (2006) are:

"More tactical, related, and broad- based than it was before. Talent management procedures comprise personnel scheduling, skill gap examination, hiring, enrollment, instruction and improvement, retention, skill reviews, succession preparation, and assessment. To propel functioning, handle a progressively more quick rate of transformation, and generate maintainable achievement, a firm has to bring into line these procedures with its business planning" (2006, p.4).

Researchers debate that to ensure the generation of abilities an unit requires to spot its asymmetries and build novel ability patterns: asymmetries refer to "talent, knowledge, procedures, associations, appropriate ties or yield that its inspired rivals will not find it easy to attain...these do not presently generate any financial benefits but have prospects to be changed into important resources or abilities" (De Wit and Meyer, 2005: 337).

\section{Talent management-A conceptual background}

The phrase "talent management" turned out to be well-known about a decade ago, when the management consulting company McKinsey stated that employers confront a "war for talents" and have difficulty in employing skilled personnel owing to stringent labor markets (Zheng et al., 2008; Collings \& Mellahi, 2009). Thereafter, the subject of talent management has amplified in significance and has received increasing attention in research papers and in business activities/practices. It is stated to be "more vital than ever before to organizational tactical achievement" and a "swiftly becoming the main precedence for organizations globally" (Boudreau \& Ramstad, 2005; Bhatnagar, 2008).

Talent Management is a system that addresses competency gaps, particularly in mission-critical occupations, by implementing and maintaining programs to attract, acquire, develop, promote, and retain quality talent. Talent management could be differentiated from conventional HRM as more tactical and futureoriented, and on par with the general business tactical aims (Schweyer, 2004; Blackman \& Kennedy, 2008; Lewis \& Heckman, 2006).

Though the expression "talent management" is extensively employed, academic research into this field is relatively fragmented. In spite of the extensive utilization of the term and its apparent significance, there is an extent of deliberation, and uncertainty about the theoretical and academic limitations of talent management. Mainly there are four major lines of perspectives related to talent management practices (Lewis \& Heckman, 2006). The first perspective is that certain researchers just replace the tag talent management with HR management. Researches in this practice frequently restrict their 
concentration to certain HR procedures like staffing, leadership improvement, succession preparation and such. The next line of researchers accentuate the improvement of skill base concentrating on "projecting employee/staffing requirements and managing the development of workers through ranks" (Lewis \& Heckman, 2006, p. 140). Third line of thought concentrates on the management of skilled personnel. Lastly, there is a surfacing fraction of researches that stress the recognition of important posts that are likely to differentially influence the competitive advantage of the company (Boudreau \& Ramstad, 2005; Becker et al., 2009). Talent is the primary driver of any successful organization. It's become increasingly obvious to most business owners and executive teams that, rather than being constrained by capital, companies are typically most constrained by talent. "Corporations have learned that, depending on what your business strategy is and what challenges you may face, at any given time you need the right talent to execute that strategy or deal with that challenge," (Gebelein 2006).

The Talent Management system is comprised of two critical success factors that work together to ensure agencies have people with the right skills, in the right places, at the right times. Addressing the critical success factors helps eliminate gaps and deficiencies in the skills, knowledge, and competencies of employees of mission-critical occupations in the current and future workforce. The two success factors usually work together are recruitment and retention. Developing a integrated talent management program will assist the organization in achieving successful organizational outcome.

\section{Research and Development}

$\mathrm{R} \& \mathrm{D}$ is an assimilative and multifaceted endeavor that needs out-of-box, innovative crisis solving and is frequently best attained by support from the shared knowledge and opinions of others
(Jassawalla \& Sashittal, 2002; Leonard \& Sensiper, 1998). R\&D actions could be managed as a procedure that could be maneuvered by the organization to give the preferred result (Tidd et al., 1997). Nevertheless, to effectively manage $\mathrm{R} \& \mathrm{D}$, the management requires to completely comprehend the background in which $R \& D$ is functioning. R\&D actions and background could be portrayed as defined in the subsequently segment. An R\&D organization, must stay competitive by developing its people. Every individual should continue to learn and develop their skills throughout their career and the organization must invest in it.

\section{Knowledge intensive}

In $R \& D$ activities, information and awareness that are present only in individuals are moved on to new abilities and are brought out as novel expertise. As per Miller and Morris (1999) the aim, ultimately, is to give new worth to consumers and concurrently generate or augment a company's competitive advantage in the market. $\mathrm{R} \& \mathrm{D}$ is also defined as a crisis-solving and knowledge gathering procedure (Browning et al., 2002). With the help of useful information created, this process of fostering knowledge also helps in adding value to the firm and contributes to its growth by reducing ambiguity or uncertainty.

Organizations globally recognize that the knowledge, talents and capabilities of their skilled personnel are the primary source of their competitive edge (Lewis \& Heckman, 2006; Collings \& Mellahi, 2009).

\section{Shortage of skill in R\&D environment}

The R\&D atmosphere is witnessing the materialization of novel means and ways of dealing with the enormous chances which have surfaced owing to the shrinking of international borders. At present, new expertise and social networks have permitted us to build pioneering advancement in spite of what were earlier 
measured as blockades, together with topography, organization, and know-how. The information and understanding that is created and to be managed is far more than what was seen earlier. Challenges are surfacing that we have not handled earlier to the degree that we require to nowadays. These challenges might be connected with: managing progressively more multifaceted internationalized joint ventures and functions, work team multiplicity, intellectual property management with manifold development associates, and altering $R \& D$ responsibilities and capabilities to mention some of them. Furthermore internationalization of engineering skill with escalating attention in China and India has resulted in complications occurring due to geographically dispersed and varied labor force.

The significance of talent management as a basis of ability improvement is observed to be additionally vital in the present circumstances owing to worldwide skills scarcity that is an extensively established occurrence (Green, 2000; Collings \& Mellahi, 2009; Aiman-Smith, Bergey, Cantwell \& Doran, 2006; Leape, 2006; Bernhart, 2006; Donaldson, 2006; Thomson, 2007; Holland, Sheehan, Donohue \& Pyman, 2007), and that renders the draw and retention of human resources more and more challenging. Numerous causes are cited for the growing challenge in sustaining workers. Firstly, the demographic nature of most emerging economies is resulting in an aging work population and in certain businesses, the people who will retire from work over the coming decade is extensive (Patrickson \& Hartmann, 1995; APSC, 2007; Strack, Baier \& Fahlander, 2008). Secondly, one notices certain trends in the interests of those being educated and, presently; this is resulting in huge skills voids in certain fields where there are insufficient number of individuals who are being trained and getting into jobs (Baker, 2006).
Individuals are perceptibly an extremely vital facet of an R\&D structure. In spite of the rising utilization of advanced instrumentation, computer simulation, and laboratory automation, $\mathrm{R} \& \mathrm{D}$ is even now a labor intensive procedure. Therefore, options about human resources like the combination of generalists vs. specialists, technological surroundings and training, work manners, professional course, lay off strategies, etc. - have a considerable effect on $R \& D$ functioning. Yet again, there is no single unsurpassed human resource plan for R\&D. Taking into consideration the lay-off strategies and career paths, certain firms unreservedly assure their R\&D staff that they would be provided with comparatively stable employment and try to find to individuals who will be inclined to continue in the firm. Other firms are contented with an extent of "churn." They do not anticipate staff to stay for long, nor do they assure job security.

\section{Talent management practices and strategies}

Talent management has become a priority for the companies around the world and hence any activity or practice related to talent management is considerably sophisticated. However, to gain competitive advantage it is not enough to design and implement talent management best practices, it is rather important to internally align various components of talent management system of a company in a proper way and embed these practices in their core value system and link it to global business coordination and various business strategies (Stahl et al., 2012).

A part of talent management practices/strategies which is most commonly practiced by the organizations is talent pool strategies. The recruitment practice that is usually followed to create a talent pool is done by recruiting best resources and then appointing them in various positions rather than recruiting specialized/specific human resource for certain 
specific positions/roles. As suggested by Hieronimus, Schaefer and Schröder (2005) companies should consider the recruits as their customers in order to exploit the brand effectively, companies should employ advanced marketing analysis to identify and determine major competitors and various corporate characteristics that are important for the recruits and have a clear understanding of these factors in order to reach out to these 'customers'. Amongst the most successful firms a common practice that is followed regularly is creating different talent pools that entail different development strategies and career path. These talent pools are based on the core competency profiles of the recruits. Beside this, a variety of diverse policies related to talent management to surmount the talents scarcities are being formulated (Romans, Frost \& Ford, 2006; ; Baxter \& MacDonald, 2007; Dewey, 2007; Archer, 2007) but several reveal a present premise of attempting to draw young talent and then sustaining it.

Managing talent in R\&D setting has become extremely crucial as R\&D institutions are now exposed to several critical challenges that include, technological evolution, increasing complexity of the domain, fierce competition of research funding and management of ever growing sophisticated modes of operations where it needs to serve industries effectively to help them raise private funds (Leitner \&Warden, 2004). Hence to gain a competitive edge in this sector companies are now trying to exploit knowledge transfer and innovation and are resorting to various talent management practices that are reaching new paradigm.

However, what is the best strategy to employ relies on the position of the R\&D labs (an architectural choice). If one is positioned in a technically advanced area like the Silicon Valley or Boston, a high "churn" method might be entirely sensible and may be inevitable. But, if the
R\&D laboratories are more geographically remote, then it is further significant to assure some amount of job security to draw talent. A skillsbased location policy permits the firm to take advantage of on the internationalized labor force and deliberation of strengths situated in the different places globally.

Keeping the trend in mind an increasing number of papers have been seen analyzing the role and significance of $R \& D$ recruits in innovation, however most of these studies mostly focus on various human resource practices and their correlation with innovation (Perez Lopez et al., 2005; Leede \& Looise, 2005; Shipton et al., 2006; Akhtar et al., 2008) than on the collaboration between various internal as well as external R\&D recruits/personnel and transfer of knowledge which play primary role in the process of innovation.

Therefore, this paper examines the effect of the role and involvement in R\&D activities of existing and recently recruited $R \& D$ talent pool on organization's innovation as well as study the effect of their collaboration and cooperation on R\&D activities.

\section{Innovation in R\&D}

Success of any organization is primarily depended on the degree of its innovativeness, which is evident by way these organizations introduce new products and ideas; the overall performance of an organization beside other factors is mainly impacted by its capacity to innovate as their future performance solely depends on the innovation of new products (Hult et al., 2004; Song \& Thieme, 2009). The process of innovation can be a structured, informal, formal or an ad-hoc process, but what plays a significant role is the collaboration between internal and external resources that help in designing and implementing innovations, research has further suggested that consistent and integrated practices help in reducing challenges related to innovations 
and enhances the speed and level of efficiency of innovativeness (Rothwell, 1994; Vermeulen, 2005).

In an $R \& D$ setting valuable innovations are primarily depended on the knowledge and skill of the expertise in the department, these valuable innovations also facilitate overall organizational success (Mallalieu, 2006). In the field of management the capacity of the organizations to innovate has been studied extensively, where researchers have been interested in evaluating the novelty of organization's innovation as that is what plays a major role in enhancing the competitive advantage of the firm and helps it to gain access to new markets (McDermott \& O'Connor, 2002; Amara \& Landry, 2005; Nieto \& Santamaria, 2007; Amara et al., 2008). The existing literature related to organizations perspective about innovation primarily focuses on the amount and quality of resources and technology used to design and implement radical innovations. This paper keeping in line with the perspective related to resources evaluates the effect of talent pool on firm's innovation.

\section{Case Study}

Premier Foods is the UK's largest food producer, branded ambient grocery manufacturer, bread baker, flour miller and leading supplier of chilled food products. The Company had to face major challenges in the year 2007. Acquisitions in 2007 significantly changed the business overnight, growing from 6,500 to 16,500 colleagues, bringing together businesses that had and hadn't focused on talent management. There was little awareness of talent or successors. First employee engagement survey indicated a dissatisfaction at talent and development processes. It was evident through follow up focus Groups that the company needed to develop and implement a companywide Talent and Succession Planning process. Company needed to reflect best practice and wanted a business led process not HR led.

In 2008, the company developed and implemented the annual Talent and Succession Management process with very clear outcomes as a part of the strategy. The process was designed in house, with external advice. A formal process is conducted annually in May, concluding in a full Board review. It also forms part of the monthly agenda of business teams. The executive review gave the organisation an overview of challenges and based on this, specific development, retention, resourcing, reward solutions and strategies were developed to address organisational needs. Newly developed strategies were focused to ensure business has the organisational capability to deliver the business strategy, to identify, retain and develop those considered to be future talent, to develop a pipeline of leaders, to identify potential successors for roles, to provide individuals with the opportunity to discuss career aspirations with their line manager, along with developing a robust development plan.

Newly developed strategies and the introduction of talent management process within Premier foods had a significant business impact, helped the company to benefit very significantly, led to the development of good leadership, improved the company's employer brand, impacted on retention and productivity and has had a significant financial impact. Measured their progress through engagement survey and have shown significant improvements. It enabled to understand organisational strength. Understanding the capabilities at all levels has enabled the organisation to develop the right people in the right way, which has ensured the ongoing delivery of their strategy. The company was awarded for its Talent management implementation by Personnel Today in the year 2011. 


\section{Findings}

The introduction of the Talent management process within Premier Foods has had a significant business impact. The periodical executive review had given the organisation an overview of challenges and based on this, specific development, retention, resourcing and reward solutions and strategies were developed to address organisational needs. Talent management plan is an essential part of organisational strategy and both are integrated. Talent availability enabled the organisation to advance its goals. Understanding the capabilities at all levels has enabled the organisation to develop the right people in the right way, which has ensured the business success.

Various significant results were drawn from the evaluation of these studies; it is observed that the most influential variable in the construct of $\mathrm{R} \& \mathrm{D}$ activities is the human resource which constitutes $44.1 \%$ of the variance, which is followed by $28.3 \%$ of variance related to financial resources. On the other hand in the construct of innovation activities the most influential factor is knowledge management with $50 \%$ variance. Results also helped in drawing certain important conclusions, firstly talent management practices such as hiring and development of $R \& D$ personnel entails strategies related to exploration of knowledge and both of these factors have positive effect on innovation when considered separately. Secondly it was also observed that collaboration between the newly hired and existing human resources in R\&D had a favorable effect on the process of innovation. This observation is supported by the fact that innovation is interactive process of learning and collaborative activities that also helps to avoid duplication of efforts, propagates results of innovative activities and helps the organization to gain competitive advantage (Hagedoorn \& Narula, 1996; Narula \& Dunning, 1997).
Nevertheless, it also observed that the process of innovation can be impacted due to issues related to the integration of knowledge of the newly hired and already existing human resource of R\&D (Kessler et al., 2000). These issues may arise when the existing resources are required to share knowledge with the new hires. Certain attitudes as stated by several authors negatively affect the knowledge sharing process such as, unconvinced of the reliability and validity of the knowledge shared/contributed by others, assumptions and beliefs that all encompassing knowledge is already existent within the area, which leads to rejection of other's ideas and preference in terms of development of organizational knowledge (Szulanski, 2000; Davenport \& Prusak, 2001; Husted \& Michailova, 2002; Goh, 2002). However researchers have suggested that these attitudes need to be changed as innovation requires knowledge sharing, and a broader mix of perspectives in order to create and implement innovative ideas (Dewar \& Dutton, 1986; McDermott \& Handfield, 2000). Hence it is important to resort to talent management activities such as retention and hiring because an organization may fall into competence trap with only existing human capital, in order to generate new innovative ideas it is important to combine knowledge and perspectives which can be accomplished through recruitment of new human resources and collaboration between new and existing human capital (Al-Laham et al., 2011). In other words for optimizing the benefits from existing talent pool, organizations must tap into new knowledge base and competencies by hiring competent talent.

The results also confirm that in order to integrate knowledge provided by external sources should be in the right context for the internal existing and newly hired R\&D personnel to be absorptive and that it should favor sophisticated degrees of innovation (Amara et al., 2008). Results also suggest that human resource policies 
related to talent management should be improvised in order to enhance the degree of innovativeness. It is thus important for $R \& D$ institutions to create an environment of trust and motivation and manage talent in a way where employees feel secure and motivated to collaborate and share knowledge in order to enhance the degree of innovativeness and competitive advantage of the firm (Goh, 2002).

Finally the overall results from both the studies reflect that human resources and proper collaboration between external and internal sources have positive effect on R\&D activities. Furthermore combination of talent and knowledge management has a positive effect on innovation. Lastly $R \& D$ activities and innovations influence the core business outcomes and contribute to the competitive advantage of the organization.

\section{Conclusion}

Human and organizational resources of an organization have an effect on the capacity of the firm to innovate (Hurley \& Hult, 1998). Various studies have shown that organizations do not necessarily posses all the knowledge for consistently engaging into innovative activities, they need to resort to external sources to gain access to new knowledge and ideas (Howells et al., 2003; Cassiman \& Veugelers, 2006; Schmiedeberg, 2008; Zhou \& Wu, 2010). Acquiring knowledge from other sources includes mechanisms such as identification, acquisition and assimilation of external knowledge (Zack, 1999). In line with this context 'learning by hiring' has been defined as acquisition of knowledge through recruitment of expertise from competing firms (Song et al., 2003). It enables to create a broader knowledge base through transfer of individual knowledge. Learning by hiring is generally used to create explicit internal knowledge base with the help of external knowledge, this especially applied in the sectors where competitive knowledge is ingrained in individual's experience and favors a higher degree of innovation (Rosenkopf \& Almeida, 2003; Dewar \& Dutton, 1986; McDermott \& Handfield, 2000; Tsai, 2009; Schoenmakers \& Duysters, 2010).

In an $R \& D$ setting from a human capital perspective, talent pool in $R \& D$ has an important role in contributing to the competitive advantage of the organization by rendering skills and knowledge needed for productive funtionalities (Rosenkopf \& Almeida, 2003; Vinding, 2006; Murovec \& Prodan, 2009; Hess \& Rothaermel, 2011). These knowledge base and level of competencies and skills offer creativity and opens up possibilities of collaboration and associations that may not have been considered before. Innovation is driven by various individual characteristics and capacity such as skill to acquire and develop new knowledge, develop or use intuitive problem solving and analytical skills, ability to integrate/assimilate knowledge acquired and last but not the least application of the acquired knowledge to generate commercial outputs (Cohen \& Levinthal, 1990; Lane et al., 2006). Organisations who engage in talent identification programmes will create the success stories of tomorrow, and leave a long standing legacy for years to come.

The findings highlight the contribution of the paper, however there are certain limitation as well that needs to be pointed out, which could offer a scope for future researches/studies. Keeping in line with these concept future studies could focus on evaluating various other/specific talent management practices that have significant impact on the process of firm's innovative activities effect. Because in an R\&D setting, organizations should know how to screen human resources, develop a talent pool and keep them motivated and also provide appropriate context for the team to share and transfer innovative ideas. 
Only specific organizational characteristics were taken into account here, future studies can focus on various other aspects/components (internally or externally) that may influence the process of innovation directly or indirectly. Lastly, future researches should concentrate on analyzing qualitatively various dimensions/ factors of talent and knowledge management activities that influence the innovation process in $R \& D$ institutions so as to provide more in-depth insight into this concept.

\section{References}

- $\quad$ Ahmed, P. K. (1998b) 'Culture and climate for innovation', European Journal of Innovation Management, 1(1), pp.30-43.

- $\quad$ Akhtar, S., Ding, D. Z. and Ge, G. L. (2008) 'Strategic HRM practices and their impact on company performance in Chinese enterprises', Human Resource Management, 47,pp. 15-32.

- $\quad$ Archer, N. (2007) Talent Management: The State Of Play: Talent Management and Organizational Effectiveness, National Institute of Governance Research Symposium, Canberra, 22 November.

- Ashton, C. andMorton, L. (2005) 'Managing talent for competitive advantage: Taking a systemic approach to talent management', Strategic HR Review, 4,pp. 28-31.

- $\quad$ Bhatnagar, J. (2008) 'Managing capabilities for talent engagement and pipeline development', Industrial and Commercial Training, 40(1), pp. 19-28.

Cappelli, P. (2008) Talent on Demand, Boston, MA: Harvard Business School Press.

- $\quad$ Frank, F. D. and Taylor, C. R. (2004) 'Talent management: Trends that will shape the future', Human Resource Planning, 27(1), pp. 33-41.

- Heinen, J. S. and O'Neill, C. (2004) 'Managing talent to maximize performance', Employment Relations Today, 31,pp. 67-8.

- Ingham, J. (2006) 'Closing the talent management gap: Harnessing your employees' talent to deliver optimum business performance', Strategic HR Review, 5, pp. 20-23.

Lewis, R. E. and Heckman, R. J. (2006) 'Talent management: A critical review', Human Resource Management Review, 16, pp. 139-154.

McCauley, C. and Wakefield, M. (2006) 'Talent management in the 21st century: Help your company find, develop and keep its strongest workers', The Journal for Quality \& Participation, 29(4), pp.4-7.

Vaiman, V. and Vance, C.M. (2008) Smart talent management: building knowledge assets for competitive advantage, Edward Elgar Publishing Ltd. 